\title{
Physico-chemical characterization of individual shortenings produced in Iran in relation to their applications
}

\author{
Jamshid Farmani $^{1}$, Mohammad Azadbakht ${ }^{2}$, Mohammad Hossein Esfahanizadeh ${ }^{1}$, Zine El \\ Abidin Babaei ${ }^{1}$, Mohammad Hossein Naeli ${ }^{3}$, and Mohsen Mardani ${ }^{1}$ \\ ${ }^{1}$ Affiliation not available \\ ${ }^{2}$ Mazandaran University of Medical Sciences \\ ${ }^{3}$ Sari Agricultural Sciences and Natural Resources University
}

May 5, 2020

\begin{abstract}
Shortenings are highly important in the food industry for being used widely in baking, confectionery, and frying products. Conventionally, shortenings are among the most important sources of trans fatty acids(TFA). In order to characterize these products, the samples from 15 different brands in Iran were collected and their physicochemical properties (fatty acid composition, iodine value(IV), free fatty acids(FFA) content, peroxide value(PV), induction periods of oxidation at $110^{\circ} \mathrm{C}(\mathrm{IP} 110)$, slip melting point(SMP), solid fat content(SFC), and Lovibond color) were studied. Briefly, Iranian shortenings contain 0.21-15.54\% of TFA and 40.08-59.54\% saturated fatty acids(SFA). Palmitic acid(25.48-47.90\%) was the dominant SFA in shortenings. The IV between 40.84 and 73.32, FFA content between $0.02-0.92 \%$ and PV between 1.0 and $3.0 \mathrm{mEq} / \mathrm{kg}$ were detected in samples. The IP110 of the samples was found to be between 10.03 and $44.02 \mathrm{~h}$. The Lovibond yellow and red colors of the samples were 2.1-13.6 and 28-70.4, respectively. SMP of the shortenings was between 42.5 and $49.3{ }^{\circ} \mathrm{C}\left(45.53{ }^{\circ} \mathrm{C}\right.$ on average). The SFC of Iranian shortenings were found to be between 40.6 and $75.0 \%$ at $10{ }^{\circ} \mathrm{C}, 24.2-59.5 \%$ at $20^{\circ} \mathrm{C}, 11.4-36.4 \%$ at $30^{\circ} \mathrm{C}, 7.8-27.3 \%$ at $35^{\circ} \mathrm{C}$, and between 3.1 and $17.4 \%$ at $40^{\circ} \mathrm{C}$. The results of this study can present valuable information on various types of shortenings to researchers and producers as the physicochemical properties of middle-eastern shortenings were characterized in great detail and were also compared with their international counterparts with reasons causing these differences in relation to slight changes in their components.
\end{abstract}

\section{Practical applications}

The results of this study can present valuable information on various types of shortenings to researchers and producers as the physicochemical properties of commercial products marketed in Iran were characterized in great detail and were also compared with some of their international counterparts and the reasons causing these differences were also discussed in this research. Hence, the present work can provide important information to researchers and industry professionals about the range of their physicochemical properties and their functional differences due to slight changes in their components.

Keywords : Characterization, Physicochemical properties, Shortening

\section{Introduction}

Shortening is a kind of edible fat which used traditionally in confectionery and bakery products. These fats are a homogeneous blend of various oils and fats, which are produced to provide desirable physicochemical and textural properties in flour and non-flour products. Shortenings prevent gluten and starch particles from adhering to each other and give the sensation of softness to the bakery products when chewed. Shortenings impart important functional properties such as tenderness and texture, aeration and stability, mouthfeel, 
heat transfer, positively contributing to the structure and geometry of the products and extended shelf-life. In bakery products, shortening increases the volume of the dough by allowing the gluten to regain its elasticity (1-3). Shortenings also help stabilize air cells produced during mixing (4).

Various types of shortenings, such as all-purpose, fluid, cake, icing, filler fat, bread, frying, pie crust, pastry, and dry shortenings are available in the food industry (1). Shortenings can be manufactured with or without emulsifiers (often mono- and diacylglycerols $(2-4 \% \mathrm{w} / \mathrm{w})$ ). Emulsified shortenings are more suitable for where the incorporation of air into the shortening system is desired (such as icings, cakes, etc.), while un-emulsified shortenings are typically used for cookies, crackers and frying (5). Final application of a shortening in the food industry typically depends on its solid fat content (SFC) profiles and oxidative stability. Such fats have to satisfy a host of nutritional, physical and rheological functionality requirements. According to the specific functionality requirements, the shortening ingredients are sometimes at odds with each other. For example, harmful trans fatty acids (TFA) are common ingredients required for good consistency and spreadability, whilst healthy essential fatty acids do not always aid in the consistency requirements (and should also be included in shortening formulation). The physical and rheological properties of shortenings depend on several factors including 1) type of fat base stocks and the amount of emulsifier; 2) the SFC profile; 3) the production process conditions (including temperature and mechanical agitation rate) (1).

Shortening production systems may, therefore, contain several steps such as blending, fractionation, hydrogenation, interesterification and tempering to obtain the desired crustal polymorph and melting characteristics. The hydrogenation is still the main technique for producing shortening in many parts of the world. Accordingly, this fat product may contain relatively high amounts of TFA (1). High levels of TFA in the diet can increase the risk of coronary heart diseases by increasing the level of triacylglycerol and the ratio of low-density lipoprotein (LDL) to high-density lipoprotein (HDL) cholesterol in blood plasma. It is specified that a $2 \%$ increase in energy intake in TFA was led to $23 \%$ increase in the risk of incidence of coronary heart disease. With increasing evidence of the harmful effects of TFA on human health such as an increased risk of cardiovascular disease and different types of allergies and cancer, studies, as well as regulatory policies, have focused on reducing the intake of TFA in diets $(6,7)$. In January 2006, the Food and Drug Administration of the United States of America (FDA) required producers to list the amount of TFAs on the nutrition facts label of conventional foods and some dietary supplements (8). Many countries such as USA, Brazil and EU countries have limits on the amount of industrialized TFAs in food products (9). In recent years, the Iranian National Standards Organization (INSO) has reduced the upper limit of TFA and saturated fatty acids (SFA) in food products. In this regard, the INSO revised the standard of specification of shortening in 2015, and changed the upper limit of TFA from 10 to $5 \%$ and SFA from no limit to $65 \%$ (10).

In recent years, many studies have been conducted to investigate the characteristics of shortenings worldwide. However, middle eastern products characteristics have not been well-studied, yet. The chemical composition and physical properties of 12 French shortenings; 73 brands of margarines and shortenings on the Danish market; and 10 Turkish shortenings have been characterized by Bayard and Wolff (11), Leth et al. (12) and Karabulut and Turan (13), respectively. Recently, Macias-Rodriguez and Marangoni (2016) investigated the rheological properties of nine commercial shortenings (including puff pastry, roll-in, all-purpose, cake and icing shortenings) with similar physicochemical characteristics but diverse functionality under small and large oscillatory shear tests (14).

In order to have accurate information on the intake of trans fats and to implement appropriate measures to reduce their intake, each country should have an updated estimate of the per capita consumption of TFA in the diet of its citizens. However, there is no report on the amount of TFA in shortenings in Iran. Other physicochemical and melting properties of this product are also not known.

In this study, the physicochemical characteristics (fatty acid composition, iodine value (IV), Lovibond color, free fatty acids (FFA), peroxide value (PV), oxidative stability index, slip melting point (SMP) and SFC) of commercial shortenings marketed in Iran were characterized. Hence, the present research can provide valuable information about different types of Iranian shortening. 


\section{Materials and Methods}

\section{Materials}

Fifteen shortening samples (5 kg) were purchased directly from the different factories in Iran (summer 2016). All samples were transferred to the laboratory, packaged and stored in a refrigerator $\left(4{ }^{\circ} \mathrm{C}\right)$ until analyses. Prior to analyses, shortening samples were molten at $60{ }^{\circ} \mathrm{C}$ to obtain homogenous samples. Chemicals were of analytical grade and purchased from Merck (Darmstadt, Germany).

\section{Fatty Acid Composition}

Fatty acid methyl esters were prepared according to the American Oil Chemists' Society (AOCS) method Ce 2-66, and analyzed using an Agilent Acme 7890B gas chromatograph (Santa Clara, the United States) equipped with a flame ionization detector and capillary chromatographic column BPX70 $(60 \mathrm{~m}, 0.25 \mathrm{~mm}$ id and $0.25 \mathrm{~mm}$ film thickness) according to AOCS method Ce 1-91 (15). Injection was performed at a split ratio of $1: 100$, the detector and injector temperature was 270 and $250{ }^{\circ} \mathrm{C}$, respectively. The column was run isothermally at $198{ }^{\circ} \mathrm{C}$, the carrier gas was nitrogen and the column head pressure was 11.79 PSI.

\section{Iodine Value}

The IV was calculated from fatty acid composition using the following formula (AOCS method Cd 1c-85 (15)): $\mathrm{IV}=(0.95 \times \% \mathrm{C} 16: 1)+(0.86 \times \% \mathrm{C} 18: 1)+(1.732 \times \% \mathrm{C} 18: 2)+(2.616 \times \% \mathrm{C} 18: 3)+(0.785 \times \% \mathrm{C} 20: 1)+(0.723 \times \% \mathrm{C} 22: 1)$

\section{Lovibond Color}

The color of samples were evaluated using Lovibond tintometer (Model E, Salisbury, England) according to AOCS method 13e-92 (15).

\section{Free Fatty Acid Content}

The FFA content was measured according to AOCS Cd 8-53 method by titration with sodium hydroxide (15).

\section{Peroxide Value}

The PV of all shortening samples was determined by the acetic acid-chloroform method in accordance with the AOCS method Cd 8-53 (15).

\section{Oxidative Stability}

The induction periods of oxidation at $110{ }^{\circ} \mathrm{C}\left(\mathrm{IP}_{110}\right)$ of samples were measured according to AOCS method Cd 12b-92 using a Methrom Rancimat instrument model 743 (Herisau, Switzerland). The tests were carried out with $2.5 \pm 0.2 \mathrm{~g}$ fat and air flow rate of $2.5 \mathrm{~mL} / \mathrm{s}(15)$.

\section{Slip Melting Point}

The SMP of the shortenings was measured in accordance with AOCS Cc 3-25 open tube melting point. The filled capillary tubes were chilled at $6 \pm 1{ }^{\circ} \mathrm{C}$ for $16 \mathrm{~h}$ before the measurements (15).

\section{Solid Fat Content}

A minispec mq 20 pulsed nuclear magnetic resonance spectroscope (Bruker Corporation, Hamburg, Germany) was used to measure SFC in samples at $10,20,30,35$ and $40{ }^{\circ} \mathrm{C}$ according to the AOCS Cd 16b-93, direct serial measurement method (15). The shortening sample was melted at $100{ }^{\circ} \mathrm{C}$ and transferred into the NMR tubes, then sample tubes were placed in an ice-bath $\left(0{ }^{\circ} \mathrm{C}\right)$ for $60 \mathrm{~min}$ before the first SFC measurement. Prior to the measurement, samples were conditioned for $35 \mathrm{~min}$ at the desired temperature.

\section{Statistical Analysis}


All the shown data represent the mean values \pm standard deviation of triplicate measurements. The mean values, standard deviations and ranges of the data were calculated using SAS software (version 9; SAS Institute, Cary, NC).

\section{Results and Discussion}

\section{Chemical Properties}

Table 1 presents the fatty acids composition of shortening samples. The TFA content of the shortenings varied between 0.21 and $15.54 \%$ (4.29\% on average). Based on definition, fat products with less than $5 \%$ and $2 \%$ TFA are referred to as low-trans and trans -free products, respectively (16). According to Table 1, only $13.33 \%$ of the samples (codes 5 and 11) were trans -free (containing less than $2 \%$ TFA). Also, $66.67 \%$ of the samples (codes 1, 2, 3, 6, 8, 9, 10,13, 14 and 15) were low-trans (containing 2-5\% TFA), and $20.00 \%$ of the samples (codes 4, 7 and 12) contained more than $5 \%$ TFA. The major trans isomer of the shortening samples was elaidic acid (Trans 18:1) with a mean content of $3.52 \%$.

Although applying more stringent regulations of maximum allowed amount of TFA was partly successful, about $20 \%$ of the shortenings found in the Iranian market still contained TFA contents of above $5 \%$, which could be the cause for concern. Unfortunately, there is no precise and reliable information on TFA content found in Iranian shortenings in previous years, but undoubtedly these series of changes in regulatory policy reduces the TFA content in Iranian shortenings.

As can be seen in Table 1, the SFA content of the shortenings was between 40.08 and $59.54 \%$ ( $50.46 \%$ on average). Palmitic acid was the main saturated fatty acid in the samples (25.48-48.90\%, $35.46 \%$ on average). This finding indicates that the palm oil and/or its derivatives (palm olein and stearin) are the main fat base stocks for production of Iranian shortenings. Oleic and linoleic acids were the dominant unsaturated fatty acids (with a range of 26.96-38.78 \% and 6.49-21.73\%, respectively). There was also a small amount of linolenic acid in Iranian shortenings (with a range of $0.11-1.83 \%, 0.66 \%$ on average), which helped their high oxidative stability.

The regulatory policy on the amount of lauric acid has recently focused on reducing the maximum level of this fatty acid in fat products due to increasing health concerns. In this regard, the INSO has determined an upper limit of $0.7 \%$ for lauric acid in the last standard amendment of shortening (10). According to Table 1 , the main content of lauric acid in Iranian shortenings was $0.26 \%$. However, the lauric acid content of sample 1 and 2 was respectively 1.08 and $1.32 \%$ which was more than the standard limit.

Leth et al. (12) characterized the properties of all shortening brands in the Danish market (39 brands) from 1995 to 1999. They observed a gradual decrease in trans isomers in the Danish shortenings: the content of TFA in this product was reduced from $10.4 \%$ in 1992 to $3.6 \%$ in 1995 and Danish shortenings were almost free from transisomers in 1999. The SFA content of Danish shortenings was 29.9-42.8\%. They also reported that palmitic acid was the dominant SFA of Danish shortenings with a range of 24.1-28.0\%.

Karabulut and Turan (13) analyzed 10 shortenings in the Turkish market from 2003 to 2004. According to their results, the TFA content of the shortenings in Turkey was 2.0-16.5 \% and SFA content was 36.3-43.1\%. Also, palmitic acid with the range of $23.8-38.4 \%$ was the predominant SFA content in Turkish shortenings, approximately similar to the Iranian case.

In general, by decreasing the maximum limit of TFA in fat products, manufacturers have to increase the SFA content in fat formulations because TFA play a significant role in consistency, plasticity, and proper melting properties. Therefore, in order to compensate for this flaw, the increase in SFA is inevitable in fat formulations (12).

The IV is one of the important parameters of oils and fats, indicating their unsaturation level. There is a direct relationship between the IV and nutrition value of fat products. The INSO specifies no limit for the IV of shortenings. According to Table 1, the IV of Iranian shortenings was between 40.84 and 73.32 (53.52 on average). 
Kheiri (17) reported the IV of 10 shortenings in the markets of Australia, Egypt, Netherlands, Japan, Kuwait, Malaysia, New Zealand, Turkey, United Arab Emirates, and United States of America as 57.0, 71.8, 67.0, $60.7,60.4,49.1,48.3,95.5,75.9$, and 84.4, respectively. Generally, it can be concluded that the IV of most Iranian shortenings is less than that of the foreign samples. Therefore, Iranian shortenings may be more saturated than the foreign ones (Table 1).

FFA content is among the most important quality parameters of oils and fats at all the processing and storage stages. These compounds are indicators for studying hydrolytic rancidity and are the secondary products of oxidation. By increasing the FFA content in fat products, the smoking point is reduced (18). According to INSO, the maximum FFA limit (wt. \% of palmitic acid) is $0.1 \%$. As can be seen in Table 2, the FFA content of the shortenings was 0.02-0.92 \%. In fact, $46.7 \%$ of the samples' (samples 5, 6, 7, 8, 9, 11, and 12) FFA contents was above the standard limit.

$\mathrm{PV}$ is an indicator of the initial oxidation products (hydrogen peroxides). Although hydrogen peroxide has no odor, the secondary products of oxidation such as aldehydes and ketones with the undesirable odor (offflavors) are produced due to the breakdown of these compounds. The PV measurement is the most common quality test for oils and fats (18).

The PV of Iranian shortenings can be seen in Table 2. The PV of the Iranian shortening samples was 1.0-3.0 $\mathrm{mEq} / \mathrm{kg}$. According to the INSO, the maximum limit of PV of shortenings should be 1,2 , and $5 \mathrm{mEq} / \mathrm{kg}$ at the time of production, for import (at the time of importing goods), and at the time of consumption, respectively. As shown in Table 2, all the shortenings had the PV of less than $5 \mathrm{mEq} / \mathrm{kg}$. In general, the samples with higher TFA and SFA contents had a lower PV; since the increase in the content of these fatty acids increases the oxidative stability of fat products.

Oxidative stability of oils and fats is affected by the presence of unsaturated fatty acids, oxygen content and storage conditions. The high content of unsaturated fatty acids accelerates the decay, thereby causing offflavors, toxic compounds, loss of nutritional value, and unusable fat products. The toxic compounds resulting from rancidity can cause problems such as tumors, heart failure, cataract, and brain dysfunction (18). The high oxidative stability is one of the most important features of shortenings, which has a great impact on the shelf-life duration of final products (1). According to INSO (10), the IP 110 of shortenings used in flour and confectionery products should be at least 30 and $25 \mathrm{~h}$. According to Table $2, \mathrm{IP}_{110}$ of the shortenings found in the Iranian market was 10.03-44.02 h. In fact, $53.3 \%$ of shortenings (samples 1, 2, 3, 5, 7, 8, 11, and 13) had the $\mathrm{IP}_{110}$ below $25 \mathrm{~h}$ and was not in the standard range. However, $46.7 \%$ of the samples (samples $4,6,9,10,12,14$, and 15 ) had $\mathrm{IP}_{110}$ above $30 \mathrm{~h}$, indicating the high oxidative stability of these samples. Unfortunately, no information can be found on the oxidative stability of shortenings in other countries.

\section{Physical Properties}

Lovibond color is a common method to check the color of oils and fats; in this method, the Lovibond color spectrophotometer is used. The major parts of a Lovibond color spectrophotometer are a series of red, yellow and blue glass standards, in which the color measurement is performed through the color control of samples with these glass color indicators (18).

Lovibond color parameters of shortenings in the Iranian market can be seen in Table 2. The Lovibond red and yellow colors of the samples were 2.1-13.6 and 28-70.4, respectively, and no blue color was found in the samples. As shown in Table 2, the Lovibond color range of the shortenings is rather wide; some samples are more colored, while others are less colored, which is due to the wide range of applications for shortenings in various food products. In fact, the type of usage of shortenings (the product that receives the shortenings) and the buyer's demand determine the Lovibond color. The yellow/red origin in the samples is the natural or added carotenoids. Processes like bleaching and deodorizing lead to thermal removal of carotenoids. Therefore, in order to compensate for the yellow/red color reduction and manufacture a product with proper and standard color features, beta-carotene is usually added to the deodorized fat (19).

Melting point is one of the most important physical properties for quality control and producing fat products. 
Factors such as non-saturation, carbon chain length, isomeric forms (cis andtrans), fatty acids and their position in the glycerol backbone, and tempering time and conditions affect the melting point of fats. SMP, which determines the beginning of melting range, is the most common one (20). In general, the shortenings should be solid at room temperature. Also, in order to prevent waxy mouthfeel, the melting point should be as close as possible to the body temperature $\left(37^{\circ} \mathrm{C}\right)(21)$.

In Table 3, the SMP of shortenings are shown. The SMP of Iranian shortenings was in the range of 42.5-49.3 ${ }^{\circ} \mathrm{C}\left(45.53{ }^{\circ} \mathrm{C}\right.$ on average). The INSO has not specified a certain limit for SMP of shortenings.

Kheiri (17) reported the SMP of 10 shortenings found in the markets of Australia, Egypt, Netherlands, Kuwait, Malaysia, New Zealand, Turkey, United Arab Emirates, Japan, and United States of America as $35.8,40.0,37.0,35.5,42.0,41.0,38.9,34.9,34.0$, and $43.0{ }^{\circ} \mathrm{C}$, respectively. Karabulut and Turan (13) studied the physicochemical properties of the 10 shortening and 15 margarine samples in the Turkish market. The SMP of Turkish shortenings and margarines was in the range of $33-43{ }^{\circ} \mathrm{C}$ and $31.2-34.9{ }^{\circ} \mathrm{C}$, respectively. They also reported that the SMP of all the shortenings was higher than that of margarines. The relatively high melting point is a desirable feature because shortening should not quickly melt at the high temperature of the oven and should lead to the stability of air cells and, as a result, a bigger product. In general, it can be concluded that the SMP of Iranian shortenings in most cases is higher than that of the foreign samples, which is quite reasonable with regard to the lower IV and higher saturation of Iranian shortenings than the foreign ones.

SFC represents the fat crystals within fats at various temperatures. It is one of the most important physical properties of fats, which directly affects many of their features such as the general appearance, ease of packaging, spreadability, consistency, textural, rheological and sensory properties $(6,22)$. This feature is not specified in INSO and there is no precise standard for it in Iran. The SFC of shortenings in the Iranian market at 10,20,30, 35 and $40^{\circ} \mathrm{C}$ is shown in Table 3. Accordingly, the SFC of Iranian shortenings at 10, $20,30,35$ and $40^{\circ} \mathrm{C}$ was $40.6-75 \%, 24.2-59.5 \%, 11.4-36.4 \%, 7.8-27.3 \%$, and 3.1-17.4 \%, respectively.

Kheiri (23) reported the SFC of 10 shortenings in the markets of Australia, Egypt, Netherlands, Kuwait, Malaysia, New Zealand, Turkey, United Arab Emirates, Japan, and United States of America at 10, 20, 30, 35 , and $40{ }^{\circ} \mathrm{C}$ as $27.1-44.3 \%, 16.6-34.1 \%, 9.7-23 \%, 5.1-13.3 \%$, and 0.0-9.6 \%, respectively.

Karabulut and Turan (13) reported that the SFC of shortenings in the Turkish market at 10, 20, 25, 30, 35 and $40^{\circ} \mathrm{C}$ was $37.9-55.6 \%, 22.4-43.5 \%, 14.9-38.4 \%, 8.3-29.4 \%, 3.3-18.3 \%$, and $0.0-8.0 \%$, respectively. According to the references, it can be concluded that the SFC of most Iranian shortenings is more than that of the majority of foreign samples (particularly at 10 and $20{ }^{\circ} \mathrm{C}$ ), which may be due to the lower IV and, consequently, the higher saturation value in Iranian shortenings (Tables 1 and 3).

The SFC curve is an indicator for evaluating the rigidity and plasticity of fats at different temperatures, from the refrigerator to the body temperature. The SFC curve can be used to determine the specific uses of fats. For example, the shortening for frying should have a steep SFC curve, while the shortening of layered pastries should have a flat SFC curve $(18,24)$.

In Fig. 1, the SFC curve of Iranian shortenings is compared with the typical SFC curve of various types of plastic fats (from the published scientific sources). As seen in Table 1, the SFC curves of most Iranian shortenings are higher than the common SFC curves of margarines and shortenings. As discussed earlier, the reason is the higher saturation of these samples than the foreign samples. Another important point is the sharper slope of SFC curve of Iranian shortenings than the common SFC curves of various margarines and shortenings. Based on Fig. 1, the SFC curve of shortenings 6, 11, 13, and 15 is more similar to the typical SFC curve of margarines and shortenings.

\section{Conclusion:}

In summary, the TFA content of the shortenings was between 0.21 and $15.54 \%$ (4.29\% on average). Merely $13.33 \%$ of the shortening samples was trans -free. Also, $66.67 \%$ of the samples was low-trans and $20 \%$ had trans- isomers of above $5 \%$. The average content of SFA and lauric acid of Iranian shortenings was $50.46 \%$ 
and $0.26 \%$, respectively. The mean FFA percentage, PV, and $\mathrm{IP}_{110}$ of the shortenings samples were $0.20 \%$, $1.67 \mathrm{mEq} / \mathrm{kg}$, and $26.89 \mathrm{~h}$, respectively. In general, the SMP and SFC values of Iranian shortenings were higher than those of the types in most of the foreign markets, which may be due to the higher saturation value of Iranian ones. The Lovibond color range of shortenings was rather wide and depended on the type of application; some samples were more colored, while others were less colored. The results of this research can present valuable information on shortenings to researchers and industries.

\section{Acknowledgements}

This research was funded in part by The Health of Plant and Livestock Products Research Center of Mazandaran University of Medical Sciences (Project No. 2516).

\section{Conflict of interest}

Authors declare no conflict of interest.

\section{References}

[1] B. S. Ghotra, S. D. Dyal, S. S. Narine, Food Res. Int. 2002, 35, 1015.

[2] A. Jang, W. Bae, H. S. Hwang, H. G. Lee, S. Lee, Food Chem. 2015, 187, 525.

[3] J. Jacob, K. Leelavathi, J. Food Eng. 2007, 79, 299.

[4] P. Given, The science of cookie and cracker production. Chaman and Hall, New York 1994.

[5] M. M. Chrysam, Bailey's industrial oil and fat products, 1985, 3, 41.

[6] M. H. Naeli, J. Farmani, A. Zargaraan, J. Food Process Eng. 2017, 2, 40.

[7] L. Ahmadi, A. G. Marangoni, Food Chem. 2009, 117, 668.

[8] T. Jeyarani, S. Y. Reddy, J. Food Lipids 2005, 12, 232.

[9] N. Costa, R. Cruz, P. Graça, J. Breda, S. Casal, Food Control. 2016, 64, 128.

[10] INSO, Edible Oils \& Fats-Shortening -Specifications and Test methods. 3rd amendment, Standard No. 156-1. Iranian National Standards Organization, Tehran, 2016.

[11] C. C. Bayard, R. L. Wolff, J. Am. Oil Chem. Soc. 1995, 72, 1485.

[12] T. Leth, A. Bysted, K. Hansen, L. Ovesen, J. Am. Oil Chem. Soc. 2003, 80, 475.

[13] I. Karabulut, S. Turan, J. Food Compost. Anal. 2006, 19, 55.

[14] B. Macias-Rodriguez, A. G. Marangoni, Rheol. Acta. 2016, 55, 767.

[15] AOCS, Official methods and recommended practices of the American Oil Chemists' Society, 4th ed. AOCS Press, Champaign, 1996.

[16] F. D. Gunstone, Modifying Lipids for Use in Food. Elsevier Science, 2006.

[17] M. S. A. Kheiri, J. Am. Oil Chem. Soc. 1985, 62, 410.

[18] R. D. O'brien, Fats and oils: formulating and processing for applications. CRC press, 3rd Ed., CRC Press, New York, 2008.

[19] D. Anderson, A primer on oils processing technology. vol 5 (Shahidi F (ed) Bailey's industrial oil and fat products), Wiley, New York, 2005, Ch. 1.

[20] M. Naeli, J. Farmani, A. Zargarran, Iranian J. Nut. Sci. Food Tech. 2016, 11, 75.

[21] G. Sheldon, Cake shortening containing acetylated monoglycerides and method of making same. (Google Patents), 1959. 
[22] P. E. D. Augusto, B. M. C. Soares, M. C. Chiu, L. A. G. Gonçalves, Food Res. Int. 2012, 45, 132.

[23] M. Kheiri, J. Am. Oil Chem. Soc. 1985, 62, 410.

[24] M. T. dos Santos, V. Gerbaud, G. Le Roux, Chem. Eng. Sci. 2013, 87, 14.

Table 1 Fatty acids composition and iodine value of Iranian commercial shortenings.

\begin{tabular}{lllllll}
\hline Fatty acid composition (\%) & \multicolumn{7}{l}{} \\
\hline & $\mathbf{1}$ & $\mathbf{2}$ & $\mathbf{3}$ & $\mathbf{4}$ & $\mathbf{5}$ & $\mathbf{6}$ \\
$\mathbf{1 2 : 0}$ & $\mathbf{1 . 0 8} \pm \mathbf{0 . 0 8}$ & $\mathbf{1 . 3 2} \pm \mathbf{0 . 0 2}$ & $\mathbf{0 . 1 1} \pm \mathbf{0 . 0 0}$ & $\mathbf{0 . 1 6} \pm \mathbf{0 . 0 0}$ & $\mathbf{0 . 0 8} \pm \mathbf{0 . 0 0}$ & $\mathbf{0 . 1 4} \pm \mathbf{0 . 0 1}$ \\
$\mathbf{1 4 : 0}$ & $\mathbf{1 . 2 5} \pm \mathbf{0 . 0 4}$ & $\mathbf{0 . 7 5} \pm \mathbf{0 . 0 3}$ & $\mathbf{0 . 7 3} \pm \mathbf{0 . 0 1}$ & $\mathbf{0 . 7 5} \pm \mathbf{0 . 0 2}$ & $\mathbf{0 . 5 2} \pm \mathbf{0 . 0 3}$ & $\mathbf{0 . 7 3} \pm \mathbf{0 . 0 1}$ \\
$\mathbf{1 6 : 0}$ & $\mathbf{4 7 . 9 0} \pm \mathbf{0 . 2 0}$ & $\mathbf{3 7 . 0 5} \pm \mathbf{0 . 3 0}$ & $\mathbf{3 8 . 0 5} \pm \mathbf{0 . 2 3}$ & $\mathbf{3 2 . 9 4} \pm \mathbf{0 . 3 3}$ & $\mathbf{2 9 . 2 7} \pm \mathbf{0 . 3 3}$ & $\mathbf{3 4 . 6 2} \pm \mathbf{0 . 4 4}$ \\
$\mathbf{1 8 : 0}$ & $\mathbf{8 . 7 6} \pm \mathbf{0 . 1 2}$ & $\mathbf{1 2 . 0 1} \pm \mathbf{0 . 2 3}$ & $\mathbf{1 2 . 2 4} \pm \mathbf{0 . 1 5}$ & $\mathbf{1 6 . 9 9} \pm \mathbf{0 . 1 8}$ & $\mathbf{9 . 5 7} \pm \mathbf{0 . 3 4}$ & $\mathbf{2 2 . 5 3} \pm \mathbf{0 . 1 5}$ \\
cis $\mathbf{1 8 : 1}$ & $\mathbf{2 9 . 2 5} \pm \mathbf{0 . 2 1}$ & $\mathbf{3 2 . 1 3} \pm \mathbf{0 . 3 2}$ & $\mathbf{3 3 . 4 5} \pm \mathbf{0 . 3 0}$ & $\mathbf{2 6 . 9 6} \pm \mathbf{0 . 2 2}$ & $\mathbf{3 5 . 5 7} \pm \mathbf{0 . 3 2}$ & $\mathbf{3 0 . 9 6} \pm \mathbf{0 . 4 1}$ \\
cis $\mathbf{1 8 : 2}$ & $\mathbf{8 . 1 8} \pm \mathbf{0 . 1 7}$ & $\mathbf{9 . 6 9} \pm \mathbf{0 . 1 6}$ & $\mathbf{9 . 9 7} \pm \mathbf{0 . 1 9}$ & $\mathbf{1 2 . 3 7} \pm \mathbf{0 . 2 0}$ & $\mathbf{2 1 . 7 3} \pm \mathbf{0 . 4 3}$ & $\mathbf{6 . 4 9} \pm \mathbf{0 . 2 5}$ \\
cis $\mathbf{1 8 : 3}$ & $\mathbf{0 . 1 1} \pm \mathbf{0 . 0 2}$ & $\mathbf{0 . 5 8} \pm \mathbf{0 . 0 0}$ & $\mathbf{0 . 6 2} \pm \mathbf{0 . 0 5}$ & $\mathbf{1 . 0 8} \pm \mathbf{0 . 0 2}$ & $\mathbf{1 . 8 3} \pm \mathbf{0 . 0 3}$ & $\mathbf{0 . 1 8} \pm \mathbf{0 . 0 0}$ \\
$\mathbf{2 0 : 0}$ & $\mathbf{0 . 4 1} \pm \mathbf{0 . 0 5}$ & $\mathbf{0 . 4 2} \pm \mathbf{0 . 0 3}$ & $\mathbf{0 . 4 3} \pm \mathbf{0 . 0 8}$ & $\mathbf{0 . 4 1} \pm \mathbf{0 . 6}$ & $\mathbf{0 . 4 1} \pm \mathbf{0 . 0 5}$ & $\mathbf{0 . 4 5} \pm \mathbf{0 . 0 1}$ \\
$\mathbf{2 0 : 1}$ & $\mathbf{0 . 1 5} \pm \mathbf{0 . 0 3}$ & $\mathbf{0 . 1 2} \pm \mathbf{0 . 0 3}$ & $\mathbf{0 . 0 0} \pm \mathbf{0 . 0 0}$ & $\mathbf{0 . 1 0} \pm \mathbf{0 . 0 0}$ & $\mathbf{0 . 1 5} \pm \mathbf{0 . 0 1}$ & $\mathbf{0 . 1 0} \pm \mathbf{0 . 0 1}$ \\
$\mathbf{2 2 : 0}$ & $\mathbf{0 . 0 7} \pm \mathbf{0 . 0 1}$ & $\mathbf{0 . 1 8} \pm \mathbf{0 . 0 0}$ & $\mathbf{0 . 1 9} \pm \mathbf{0 . 0 3}$ & $\mathbf{0 . 1 5} \pm \mathbf{0 . 0 2}$ & $\mathbf{0 . 1 7} \pm \mathbf{0 . 0 2}$ & $\mathbf{0 . 1 1} \pm \mathbf{0 . 0 0}$ \\
$\mathbf{2 4 : 0}$ & $\mathbf{0 . 0 7} \pm \mathbf{0 . 0 2}$ & $\mathbf{0 . 0 8} \pm \mathbf{0 . 0 0}$ & $\mathbf{0 . 0 8} \pm \mathbf{0 . 0 0}$ & $\mathbf{0 . 0 8} \pm \mathbf{0 . 0 1}$ & $\mathbf{0 . 0 6} \pm \mathbf{0 . 0 1}$ & $\mathbf{0 . 0 7} \pm \mathbf{0 . 0 0}$ \\
trans $\mathbf{1 8 : 1}$ & $\mathbf{1 . 9 8} \pm \mathbf{0 . 0 7}$ & $\mathbf{3 . 7 7} \pm \mathbf{0 . 0 4}$ & $\mathbf{3 . 3 4} \pm \mathbf{0 . 0 2}$ & $\mathbf{7 . 2 4} \pm \mathbf{0 . 0 2}$ & $\mathbf{0 . 0 0} \pm \mathbf{0 . 0 0}$ & $\mathbf{2 . 7 5} \pm \mathbf{0 . 0 2}$ \\
trans $\mathbf{1 8 : 2}$ & $\mathbf{0 . 0 9} \pm \mathbf{0 . 0 0}$ & $\mathbf{0 . 7 7} \pm \mathbf{0 . 0 0}$ & $\mathbf{0 . 5 1} \pm \mathbf{0 . 0 7}$ & $\mathbf{0 . 1 9} \pm \mathbf{0 . 0 7}$ & $\mathbf{0 . 2 1} \pm \mathbf{0 . 0 0}$ & $\mathbf{0 . 0 9} \pm \mathbf{0 . 0 0}$ \\
TFA & $\mathbf{2 . 0 7}$ & $\mathbf{4 . 5 4}$ & $\mathbf{3 . 8 5}$ & $\mathbf{7 . 4 3}$ & $\mathbf{0 . 2 1}$ & $\mathbf{2 . 8 4}$ \\
SFA & $\mathbf{5 9 . 5 4}$ & $\mathbf{5 1 . 8 1}$ & $\mathbf{5 1 . 8 3}$ & $\mathbf{5 1 . 4 8}$ & $\mathbf{4 0 . 0 8}$ & $\mathbf{5 8 . 6 5}$ \\
SFA+TFA & $\mathbf{6 1 . 6 1}$ & $\mathbf{5 6 . 3 5}$ & $\mathbf{5 5 . 6 8}$ & $\mathbf{5 8 . 9 1}$ & $\mathbf{4 0 . 2 9}$ & $\mathbf{6 1 . 4 9}$ \\
USFA & $\mathbf{3 7 . 6 9}$ & $\mathbf{4 2 . 5 2}$ & $\mathbf{4 4 . 0 4}$ & $\mathbf{4 0 . 5 1}$ & $\mathbf{5 9 . 2 8}$ & $\mathbf{3 7 . 7 3}$ \\
\hline
\end{tabular}

Table 2 The free fatty acids content, peroxide value, induction period of oxidation at $110{ }^{\circ} \mathrm{C}$ and lovibond color of Iranian commercial shortenings.

\begin{tabular}{|c|c|c|c|c|c|}
\hline Shortening code & Free fatty acids content (\%) & Peroxide value(meq/kg) & $\mathrm{IP}_{110}(\mathrm{~h})$ & Lovibond color & Lo \\
\hline & & & & Red & \\
\hline 1 & $0.06 \pm 0.01$ & $1.20 \pm 0.02$ & $20.10 \pm 0.30$ & $3.80 \pm 0.40$ & \\
\hline 2 & $0.05 \pm 0.02$ & $1.50 \pm 0.01$ & $21.67 \pm 0.62$ & $5.20 \pm 0.20$ & 7 \\
\hline 3 & $0.02 \pm 0.01$ & $1.20 \pm 0.32$ & $18.34 \pm 0.20$ & $13.60 \pm 0.10$ & \\
\hline 4 & $0.09 \pm 0.03$ & $1.80 \pm 0.13$ & $36.22 \pm 0.53$ & $11.20 \pm 0.40$ & \\
\hline 5 & $0.92 \pm 0.02$ & $2.00 \pm 0.11$ & $11.68 \pm 0.41$ & $7.60 \pm 0.50$ & \\
\hline 6 & $0.59 \pm 0.01$ & $1.20 \pm 0.04$ & $38.42 \pm 0.45$ & $8.70 \pm 0.60$ & \\
\hline 7 & $0.11 \pm 0.04$ & $1.40 \pm 0.05$ & $10.46 \pm 0.80$ & $6.80 \pm 0.40$ & \\
\hline 8 & $0.25 \pm 0.02$ & $1.40 \pm 0.10$ & $18.54 \pm 0.22$ & $11.50 \pm 0.80$ & \\
\hline 9 & $0.39 \pm 0.04$ & $1.00 \pm 0.00$ & $38.02 \pm 0.25$ & $10.80 \pm 0.40$ & \\
\hline 10 & $0.05 \pm 0.02$ & $2.50 \pm 0.20$ & $39.51 \pm 0.21$ & $8.40 \pm 0.20$ & \\
\hline 11 & $0.16 \pm 0.05$ & $1.80 \pm 0.32$ & $10.30 \pm 0.57$ & $6.30 \pm 0.50$ & \\
\hline 12 & $0.12 \pm 0.02$ & $3.00 \pm 0.14$ & $34.46 \pm 0.90$ & $3.10 \pm 0.20$ & \\
\hline 13 & $0.04 \pm 0.00$ & $2.00 \pm 0.13$ & $21.44 \pm 0.81$ & $2.10 \pm 0.20$ & \\
\hline 14 & $0.08 \pm 0.01$ & $1.40 \pm 0.06$ & $40.72 \pm 0.74$ & $4.50 \pm 0.60$ & \\
\hline 15 & $0.08 \pm 0.01$ & $1.60 \pm 0.12$ & $44.02 \pm 0.89$ & $5.90 \pm 0.70$ & \\
\hline Mean \pm SD & $0.20 \pm 0.25$ & $1.67 \pm 0.54$ & $26.89 \pm 0.26$ & - & \\
\hline
\end{tabular}


Table 3 The slip melting point and solid fat content of Iranian commercial shortenings.

\begin{tabular}{lllllll}
\hline Shortening code & \multicolumn{5}{c}{$\mathrm{SFC}(\%)$} \\
\hline & ${ }^{\circ} \mathrm{C} 10$ & ${ }^{\circ} \mathrm{C} 20$ & ${ }^{\circ} \mathrm{C} 30$ & ${ }^{\circ} \mathrm{C} 35$ & ${ }^{\circ} \mathrm{C} 40$ & \\
1 & $70.5 \pm 0.1$ & $54.5 \pm 0.7$ & $33.3 \pm 1.0$ & $25.4 \pm 0.2$ & $16.5 \pm 0.5$ & $46.0 \pm 0.3$ \\
2 & $64.70 \pm 0.9$ & $45.7 \pm 1.0$ & $25.5 \pm 0.4$ & $19.3 \pm 0.8$ & $12.1 \pm 0.3$ & $43.0 \pm 0.1$ \\
3 & $67.0 \pm 0.9$ & $50.8 \pm 0.6$ & $32.5 \pm 0.5$ & $24.5 \pm 0.7$ & $14.8 \pm 0.3$ & $48.2 \pm 0.4$ \\
4 & $75.0 \pm 0.8$ & $59.5 \pm 0.6$ & $36.4 \pm 0.9$ & $27.3 \pm 0.6$ & $17.4 \pm 0.2$ & $48.0 \pm 0.1$ \\
5 & $40.6 \pm 0.1$ & $24.2 \pm 0.9$ & $11.4 \pm 0.7$ & $7.9 \pm 0.8$ & $4.0 \pm 0.6$ & $46.3 \pm 0.2$ \\
6 & $43.5 \pm 0.8$ & $25.6 \pm 0.7$ & $12.3 \pm 0.6$ & $8.1 \pm 0.5$ & $3.1 \pm 0.5$ & $43.0 \pm 0.3$ \\
7 & $64.6 \pm 0.6$ & $47.7 \pm 0.8$ & $27.7 \pm 0.9$ & $20.1 \pm 0.3$ & $12.1 \pm 0.7$ & $45.1 \pm 0.2$ \\
8 & $65.3 \pm 0.4$ & $49.0 \pm 0.4$ & $29.6 \pm 0.5$ & $21.6 \pm 0.2$ & $13.2 \pm 0.8$ & $49.3 \pm 0.5$ \\
9 & $70.6 \pm 0.7$ & $56.9 \pm 0.6$ & $35.2 \pm 0.9$ & $26.6 \pm 0.6$ & $16.5 \pm 0.7$ & $47.0 \pm 0.1$ \\
10 & $66.8 \pm 0.5$ & $50.2 \pm 0.5$ & $28.5 \pm 0.6$ & $20.6 \pm 0.8$ & $12.0 \pm 0.6$ & $44.2 \pm 0.3$ \\
11 & $45.5 \pm 0.9$ & $27.2 \pm 0.4$ & $13.1 \pm 0.4$ & $8.8 \pm 0.3$ & $3.8 \pm 0.6$ & $44.5 \pm 0.1$ \\
12 & $68.8 \pm 0.6$ & $50.8 \pm 0.4$ & $25.9 \pm 0.9$ & $15.8 \pm 0.6$ & $6.9 \pm 0.3$ & $43.1 \pm 0.3$ \\
13 & $51.8 \pm 0.7$ & $29.6 \pm 0.5$ & $12.5 \pm 0.6$ & $7.8 \pm 0.2$ & $3.6 \pm 0.1$ & $47.3 \pm 0.5$ \\
14 & $60.2 \pm 1.1$ & $38.0 \pm 0.6$ & $18.9 \pm 0.2$ & $14.2 \pm 0.5$ & $9.6 \pm 0.6$ & $45.5 \pm 0.1$ \\
15 & $58.8 \pm 0.9$ & $37.4 \pm 0.3$ & $17.6 \pm 0.6$ & $11.8 \pm 0.5$ & $6.6 \pm 0.1$ & $42.5 \pm 0.5$ \\
Mean $\pm \mathrm{SD}$ & $60.9 \pm 10.7$ & $43.1 \pm 11.89$ & $24.0 \pm 8.9$ & $17.3 \pm 7.1$ & $10.15 \pm 5.1$ & $45.53 \pm 2.15$ \\
\hline
\end{tabular}

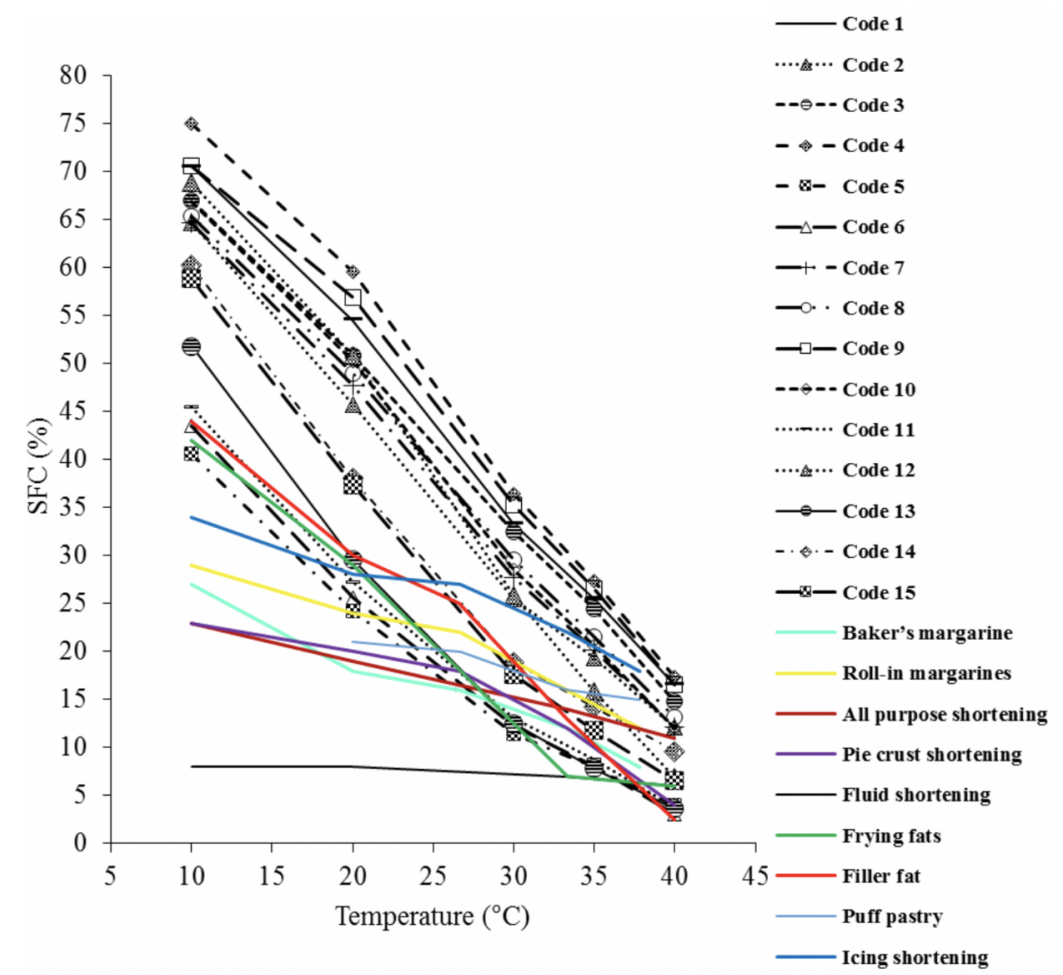

Fig. 1 Comparison of solid fat content (SFC) curve of Iranian commercial shortenings with baker's margarine, Roll-in margarines, all-purpose shortening, pie crust shortening, fluid shortening, frying fags, filler 
fat, puff pastry and icing shortening. 